\title{
Pinealectomy increases thermogenesis and decreases lipogenesis
}

\author{
MIKYUNG KIM ${ }^{1 *}$, SO MIN LEE ${ }^{2 *}$, JEEYOUN JUNG $^{2}$, YUN JIN KIM ${ }^{1}$, \\ KYO CHUL MOON $^{1}$, JI HAE SEO ${ }^{1}$, TAE KYUNG HA ${ }^{3}$ and EUNYOUNG HA ${ }^{1}$ \\ ${ }^{1}$ Department of Biochemistry, School of Medicine, Keimyung University, Daegu 42601; \\ ${ }^{2}$ Clinical Medicine Division, Korea Institute of Oriental Medicine, Daejeon 34054; ${ }^{3}$ Department of Surgery, \\ Hanyang University College of Medicine, Seoul 04763, Republic of Korea
}

Received December 21, 2019; Accepted July 16, 2020

DOI: $10.3892 / \mathrm{mmr} .2020 .11534$

\begin{abstract}
The present study was designed to determine the effects of pineal gland-derived melatonin on obesity by employing a rat pinealectomy (Pnx) model. After 10 weeks of a high-fat diet, rats received sham or Pnx surgery followed by a normal chow diet for 10 weeks. Reverse transcription-quantitative PCR, western blotting analysis, immunohistochemistry and ELISA were used to determine the effects of Pnx. Pnx decreased the expression of melatonin receptor (MTNR)1A and MTNR1B, in brown adipose tissues (BAT) and white adipose tissues (WAT). Pnx rats showed increased insulin sensitivity compared with those that received sham surgery. Leptin levels were significantly decreased in the serum of the Pnx group. In addition, Pnx stimulated thermogenic genes in BAT and attenuated lipogenic genes in both WAT and the liver. Histological analyses revealed a marked decrease in the size of lipid droplets and increased expression of uncoupling protein 1 in BAT. In the liver of the Pnx group, the size and
\end{abstract}

Correspondence to: Professor Eunyoung Ha, Department of Biochemistry, School of Medicine, Keimyung University, 1095 Dakgubeoldaero, Daegu 42601, Republic of Korea

E-mail: eyha@dsmc.or.kr

Professor Tae Kyung Ha, Department of Surgery, Hanyang University College of Medicine, 222 Wangsimliro, Seoul 04763, Republic of Korea

E-mail: missurgeon@hanyang.ac.kr

${ }^{*}$ Contributed equally

Abbreviations: Pnx, pinealectomy; HFD, high-fat diet; NCD, normal chow diet; MTNR, melatonin receptor; BAT, brown adipose tissue; WAT, white adipose tissue; UCP1, uncoupling protein 1; PGTT, peritoneal glucose tolerance test; SIRT1, sirtuin 1; PGC1 $\alpha$, peroxisome proliferator-activated receptor $\gamma$ coactivator-1 $\alpha$; PRDM16, PR domain-containing 16; SREBP1c, sterol regulatory element binding protein 1c; FASN, fatty acid synthase; SCD1, stearoyl-CoA desaturase; $\mathrm{CPT}$, carnitine palmitoyltransferase; MCAD, medium-chain acyl-CoA dehydrogenase; Cyt c, cytochrome c

Key words: pinealectomy, melatonin, brown adipose tissue, thermogenesis, lipogenesis number of lipid droplets had also decreased. In conclusion, the results presented in the current study suggested that Pnx increases thermogenesis in BAT and decreases lipogenesis in WAT and the liver.

\section{Introduction}

Disorders associated with individuals being overweight and obese have become everyday issues over the past few decades, and global statistics indicate that these disorders are on a continuous rise (1). Obesity is a metabolic syndrome that is associated with a cluster of disorders, including type 2 diabetes mellitus, hypertension and fatty liver disorder (2-5). Despite the increasing life expectancy in the United States, babies born at the beginning of the twenty-first century are predicted to be the first generation that may have shorter life expectancies than their parents (6). Risk factors for becoming overweight and obese are well known, but the underlying pathogenesis has not yet been elucidated. At present, therapy is aimed at modifying the risk factors, but there are no sustainable therapies for the prevention or treatment of obesity.

Melatonin is a neurohormone synthesized in the pineal gland (7). It exerts its functions via membrane and nuclear receptors as well as receptor-independent actions. Receptor-mediated neuroendocrine functions of melatonin include the circadian rhythm, sleep, the stress response, the process of aging and immunity $(8,9)$. The antioxidant effect of melatonin, along with the free radical scavenging action, is a well-established receptor-independent function (10).

Melatonin has various functions, including the promotion and regulation of energy homeostasis (11). For instance, evidence has demonstrated that melatonin is involved in the regulation of food intake, energy storage and energy expenditure $(12,13)$. Melatonin treatment in drinking water or a liquid diet has been revealed to reduce body weight and abdominal fat in rats independently of food intake reduction (14-17). In the zebrafish, melatonin inhibits appetite and stimulates satiety signals in the central nervous system (18). A previous study has also indicated that there is a synchronizing function of melatonin with the metabolism in white adipocytes (19).

Although studies with exogenous administration of melatonin demonstrate the 'anti-obesity' effect of melatonin, as aforementioned, the effects of endogenous melatonin on obesity are controversial and have not yet been established. 
Thus, the aim of the current study was to determine the effects of endogenous melatonin, especially pineal gland-derived, on obesity by employing rat pinealectomy (Pnx) model.

\section{Materials and methods}

Animals. A total of 23 male Wistar rats, aged 3-weeks-old, were purchased from the Laboratory Animal Center of Japan SLC, Inc. The rats were housed in individual cages under a controlled temperature $\left(24 \pm 1^{\circ} \mathrm{C}\right)$, humidity and lighting $(12$-h light/dark cycle). After 1-week of acclimation, rats were fed a high-fat diet (HFD; cat. no. D12451; Research Diets, Inc.) for 10 weeks, which contained $45 \% \mathrm{kcal}$ as fat, $20 \%$ as protein and $35 \%$ as carbohydrates, with access to water ad libitum prior to the operation. Rats were randomized into two groups with a similar average body weight, the sham group with 13 ats, and the Pnx group with 10 rats. After the operation, rats were fed a normal chow diet (NCD) with access to water ad libitum for 10 weeks. This study was approved by the Institutional Animal Care and Use Committee of Keimyung University, School of Medicine, Daegu, Korea (approval number. KM-2014-16). Body weight, food intake and water intake were measured twice a week. Peritoneal glucose tolerance tests (PGTT) were performed before and after the operation on overnight-fasted rats. After an overnight fast, rats were administrated with $1 \mathrm{~g} / \mathrm{kg}$ glucose [D-(+)-glucose; Sigma-Aldrich; Merck KGaA] by peritoneal gavage. Blood samples were collected from the tip of the tail immediately prior to and 30,60,90 and $120 \mathrm{~min}$ after injection. Blood glucose was measured using a glucometer (Model GU, Accu-Chek Active; Roche Diagnostics GmbH). Rats were sacrificed by isoflurane [2\% volume-to-volume (v/v) concentration] inhalation at 10 weeks after operation followed by exsanguination. Tissues, including brown adipose tissues (BAT) and white adipose tissues (WAT), and serum were harvested for further analyses.

Surgical procedures. Rats were fasted overnight prior to surgery. Pnx was performed as described previously (20). Anesthesia was induced with an isoflurane concentration (v/v) of 5\% (JW Pharmaceutical Corporation) in 30\% oxygen and $70 \%$ nitrous oxide and maintained with $2 \%$ isoflurane (v/v) during the surgical procedure. In brief, a sagittal opening was made in the scalp followed by exposure of the lambda suture. The skull around the lambda suture was drilled and carefully removed. The pineal gland was then removed with fine forceps. The removed skull was placed back, and the scalp was sutured. The procedure was completed within $30 \mathrm{~min}$.

Reverse transcription-quantitative polymerase chain reaction $(R T-q P C R)$. Total RNA was extracted with TRIzol ${ }^{\circledR}$ reagent (Invitrogen; Thermo Fisher Scientific, Inc.) according to the manufacturer's protocol. For RT-qPCR, $5 \mu \mathrm{g}$ total RNA was reverse transcribed for $30 \mathrm{~min}$ at $37^{\circ} \mathrm{C}$ in a reaction mixture containing the RNA, $40 \mathrm{U}$ RNase inhibitor (Promega Corporation), $0.5 \mathrm{mM}$ deoxynucleotide triphosphate (Promega Corporation), $2 \mu \mathrm{M}$ random hexamer primers, 5X AMV reverse transcriptase reaction buffer and $30 \mathrm{U}$ AMV reverse transcriptase (Promega Corporation). RT-qPCR analysis was performed using the SYBR Green PCR Master Mix (Toyobo Life Science) and RT-qPCR thermocycling conditions were as follows: Initial denaturation at $95^{\circ} \mathrm{C}$ for $30 \mathrm{sec}$, followed by amplification for 45 cycles performed at $95^{\circ} \mathrm{C}$ for $5 \mathrm{sec}, 60^{\circ} \mathrm{C}$ for $10 \mathrm{sec}$ and $72^{\circ} \mathrm{C}$ for $15 \mathrm{sec}, 95^{\circ} \mathrm{C}$ for $10 \mathrm{sec}$ and $10 \mathrm{sec}$ each at $0.2^{\circ} \mathrm{C}$ increments to $62^{\circ} \mathrm{C}$ for a melting curve analysis, and $65^{\circ} \mathrm{C}$ for $1 \mathrm{~min}$, followed by cooling to $37^{\circ} \mathrm{C}$ for $10 \mathrm{~min}$ with gene-specific primers. The relative expression of each gene was normalized against $\beta$-actin. The samples were assayed on a LightCycler 480 (Roche Diagnostics) instrument and the concentration was calculated as copies per $\mu \mathrm{l}$ using the standard curve. Primer sequences (Macrogen, Inc.) are listed in Table I.

Western blot analysis. Harvested tissues were subjected to SDS-PAGE and immunoblotted. Briefly, tissues were lysed in ice-cold lysis buffer [50 mM Tris- $\mathrm{HCl}(\mathrm{pH}, 7.4), 25 \mathrm{mM}$ EDTA (pH 8.0), $650 \mathrm{mM} \mathrm{NaCl}, 5 \%$ Triton X-100] containing protease inhibitors $(200 \mathrm{mM}$ phenylmethylsulfonyl fluoride, $100 \mu \mathrm{g} / \mathrm{ml}$ leupeptin, $10 \mu \mathrm{g} / \mathrm{ml}$ pepstatin, $1 \mu \mathrm{g} / \mathrm{ml}$ aprotinin and $2 \mathrm{mM}$ EDTA). The lysates were centrifuged for $20 \mathrm{~min}$ at $7,500 \mathrm{x} \mathrm{g}$ at $4^{\circ} \mathrm{C}$ and the supernatant was collected. The concentrations of protein were determined using a BCA protein assay kit (cat. no. 23227; Thermo Fisher Scientific, Inc.) and densitometric analysis was performed using SPECTROstar Nano software (version 5.5; BMG Labtech GmbH). Proteins (30 $\mu \mathrm{g})$ were separated by SDS-PAGE (8\%) and transferred to nitrocellulose membrane (GE Healthcare). The membrane was blocked at room temperature (RT) for $30 \mathrm{~min}$ in $5 \%$ skimmed milk in TBS with $0.1 \%$ Tween-20 (TBST) before incubation overnight at $4^{\circ} \mathrm{C}$ with the following primary antibodies: Anti-uncoupling protein 1 (UCP1; 1:1,000; cat. no. ab10983; Abcam), anti-peroxisome proliferator-activated receptor $\gamma$ coactivator- $1 \alpha$ (PGCl $\alpha$; 1:500; cat. no. ab54481; Abcam), anti-iodothyronine deiodinase 2 (DIO2; 1:1,000; cat. no. ab77779; Abcam), anti-p-Akt (1:1,000; cat. no. 9271S; Cell Signaling Technology, Inc.), MTNR1A (1:1,000; cat. no. NBP1-7113; Novus Biologicals, LLC), MTNR1B (1:1,000; cat. no. NLS932; Novus Biologicals) and anti-sirtuin 1 (SIRT1; 1:1,000; cat. no. sc-15404; Santa Cruz Biotechnology, Inc.). $\beta$-actin $(1: 1,000$; cat. no. A5441; Sigma-Aldrich; Merck KGaA) was used as an internal control. The membrane was then washed in TBST and incubated with horseradish peroxidase-conjugated rabbit and mouse secondary antibodies (both 1:1,000; cat. nos. sc-2004 and sc-2005, respectively; both Santa Cruz Biotechnology, Inc.). Protein bands were detected using Super Signal West Pico Chemiluminescent Substrate (Thermo Fisher Scientific, Inc.). The protein-specific signals were detected using LAS-3000 (FujiFilm Wako Pure Chemical Corporation).

Histological assessment of BAT. The BAT of each rat was fixed at RT for $24 \mathrm{~h}$ with $10 \%$ formalin, embedded in paraffin and sectioned. The sections ( $4 \mu \mathrm{m}$-thick) were stained at RT with hematoxylin and eosin (H\&E) for $3 \mathrm{~min}$ and $30 \mathrm{sec}$, respectively, or immunohistochemistry was performed for light microscopic examination. To observe UCP1 expression, $5-\mu \mathrm{m}$ thick sections were permeabilized in PBS, incubated in $10 \mathrm{mM}$ sodium citrate buffer with $\mathrm{pH} 6.0$ at $100^{\circ} \mathrm{C}$ for $10 \mathrm{~min}$, and then incubated with anti-UCP1 (1:3,000 antibody overnight at $4^{\circ} \mathrm{C}$. Sections were then incubated with the secondary UCP1 antibody (1:200; Santa Cruz Biotechnology, Inc.) for $1 \mathrm{~h}$ at RT, followed by staining at RT for $1 \mathrm{~min}$ with diaminobenzidine 
Table I. Primer sequences.

\begin{tabular}{|c|c|c|c|}
\hline Gene & Sequence $\left(5^{\prime} \rightarrow 3^{\prime}\right)$ & Temperature, ${ }^{\circ} \mathrm{C}$ & $\mathrm{bp}$ \\
\hline CPT1A & $\begin{array}{l}\text { F: ATGACGGCTATGGTGTCTCC } \\
\text { R: GTGAGGCCAAACAAGGTGAT }\end{array}$ & 60 & 154 \\
\hline СРТ1B & $\begin{array}{l}\text { F: CTGGACCGAGAAGAGATCAA } \\
\text { R: CCTTGAAGAAGCGACCTTTG }\end{array}$ & 60 & 175 \\
\hline Cyt C & $\begin{array}{l}\text { F: TCAATGATGCTGCCTTTCAC } \\
\text { R: ACTCCCAATCAGGCATGAAC }\end{array}$ & 60 & 233 \\
\hline DIO2 & $\begin{array}{l}\text { F: TCCCAATTCCAGTGTGGTGC } \\
\text { R: GCGGAAGGCTGGCAGTTGCC }\end{array}$ & 61 & 181 \\
\hline FASN & $\begin{array}{l}\text { F: TGGCTTCCGTTCAGTCTCTT } \\
\text { R: CAGTGCCAAGGTCTCTAGCC }\end{array}$ & 60 & 180 \\
\hline MCAD & $\begin{array}{l}\text { F: CCTGGACAGGAAAACATTTG } \\
\text { R: CCTTCGCAATAGAGGCAAAG }\end{array}$ & 60 & 167 \\
\hline MTNR1A & $\begin{array}{l}\text { F: CAGACCTCGTGGTGGCTATT } \\
\text { R: TCAGGAACACGTAGCACAGG }\end{array}$ & 60 & 237 \\
\hline MTNR1B & $\begin{array}{l}\text { F: ATTCCTGCACCTTCATCCAG } \\
\text { R: TATGGCGAAAACCACAAACA }\end{array}$ & 60 & 224 \\
\hline $\mathrm{PGC} 1 \alpha$ & $\begin{array}{l}\text { F: TCGCCTTCTTGCTCTTCCTT } \\
\text { R: ATCTACTGCCTGGGGACCTT }\end{array}$ & 59 & 175 \\
\hline PRDM16 & $\begin{array}{l}\text { F: CCTAGCCCTGAGCGATACTG } \\
\text { R: AGTAGCTACGTTGCGGGAGA }\end{array}$ & 61 & 233 \\
\hline SREBP1c & $\begin{array}{l}\text { F: GTGGTCTTCCAGAGGCTGAG } \\
\text { R: GGGTGAGAGCCTTGAGACAG }\end{array}$ & 62 & 178 \\
\hline UCP1 & $\begin{array}{l}\text { F: GAAGGATTGCCGAAACTGTA } \\
\text { R: CCAGCCGAGATCTTGCTTCC }\end{array}$ & 57 & 155 \\
\hline$\beta$-actin & $\begin{array}{l}\text { F: AGCCATGTACGTAGCCATCC } \\
\text { R: TTTCCCTCTCAGCTGTGGTG }\end{array}$ & 60 & 233 \\
\hline
\end{tabular}

F, forward; R, reverse; CPT, carnitine palmitoyltransferase; Cyt C, cytochrome c; DIO2, deiodinase 2; FASN, Fatty acid synthase; MCAD, medium-chain acyl-CoA dehydrogenase; MTNR, melatonin receptor; PGC1 $\alpha$, peroxisome proliferator-activated receptor gamma coactivator 1-alpha; PRDM16, PR domain containing 16; SREBP1c, Sterol regulatory element-binding protein 1; UCP1, Uncoupling protein 1; bp, base pair.

chromogen (Vector Laboratories, Inc.) and counterstaining with hematoxylin at RT for $3 \mathrm{~min}$. The stained sections were examined under a microscope at magnification x200 (Nikon Corporation); all histological assessments were made by a pathologist.

Enzyme-linked immunosorbent assay (ELISA). Blood samples were allowed to clot for $2 \mathrm{~h}$ at RT before centrifugation at $4^{\circ} \mathrm{C}$ for $20 \mathrm{~min}$ at $2,000 \mathrm{x} \mathrm{g}$. Serum levels of leptin (R\&D System, Inc.) and melatonin (cat. no. CEA908GE; Cloud-Clone Corp.) were measured using ELISA kits. Enzyme levels in the supernatants were measured according to the manufacturer's instructions. Serum samples were then diluted at 1:10 in a diluent solution from the kit and incubated in the plates at RT for $2 \mathrm{~h}$, after which the plates were washed five times with washing buffer from the kit. Horseradish peroxidase conjugated rat leptin $(100 \mu \mathrm{l})$ was added and then incubated for $2 \mathrm{~h}$ at RT. The plates were washed five times and incubated with substrate solution for $30 \mathrm{~min}$, after which the stop solution was added. The absorbance values were determined with an ELISA microplate reader (Biochrom, Ltd.) at a wavelength of $450 \mathrm{~nm}$ and then $570 \mathrm{~nm}$. Hepatic triglyceride (TG; cat. no. 10010303; Cayman Chemical Company) levels were measured using an ELISA kit. Briefly, the samples or TG standard were incubated with TG enzyme mixture in plates for $15 \mathrm{~min}$ at RT. A standard curve was constructed to assign arbitrary units. The absorbance values were determined with an ELISA microplate reader operating at $530-550 \mathrm{~nm}$.

Statistical analysis. Data were analyzed using an unpaired Student's t-test. Each experiment was performed at least three times in duplicate. All data are given in terms of relative values and are presented as the mean \pm standard deviation. $\mathrm{P}<0.05$ was considered to indicate a statistically significant difference. 

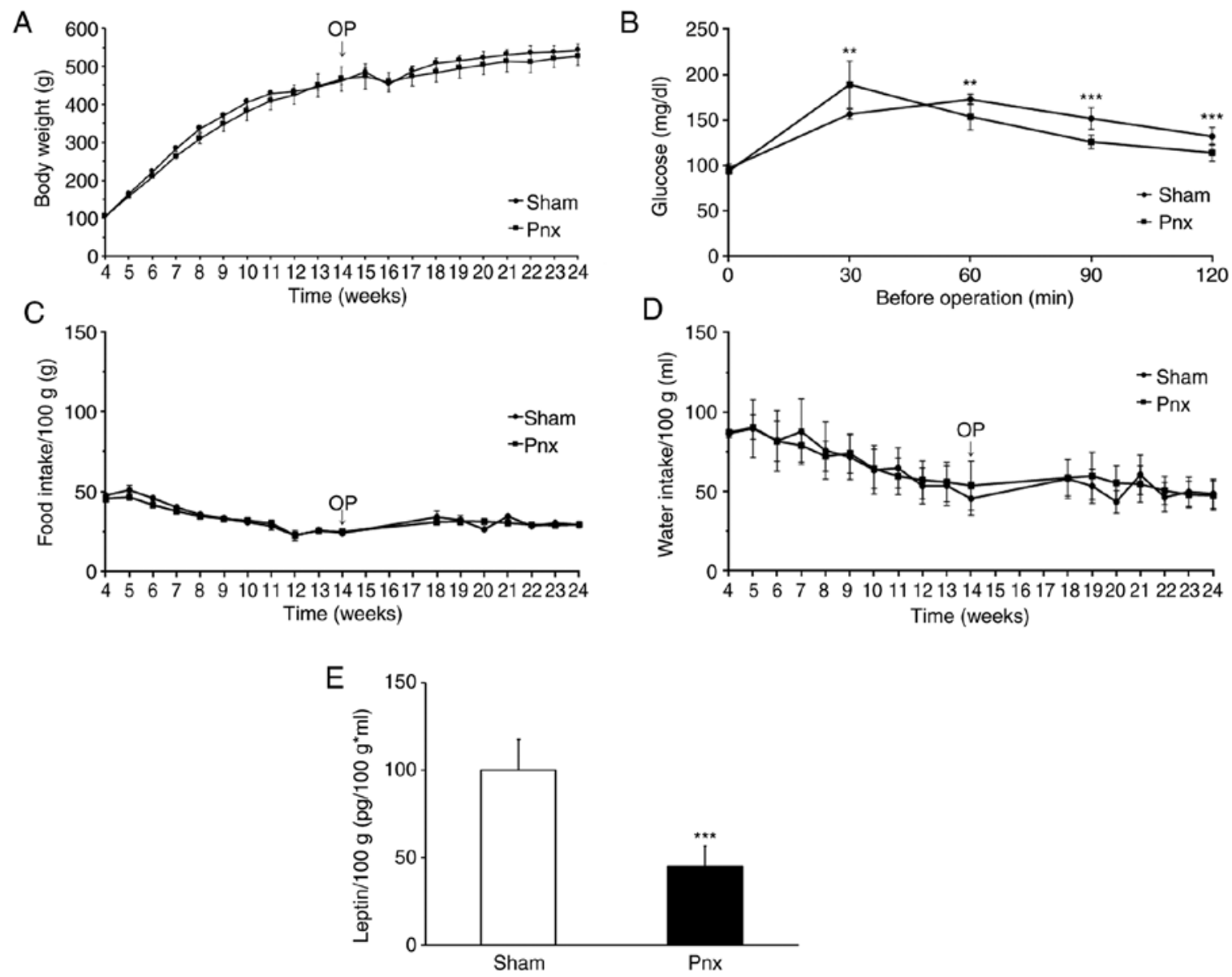

Figure 1. Pnx increases insulin sensitivity. (A) Changes in body weight, (B) PGTT, (C) food intake, (D) water intake and (E) plasma leptin levels. Values are presented as the mean $\pm \mathrm{SD} .{ }^{* *} \mathrm{P}<0.01,{ }^{* * *} \mathrm{P}<0.001$ vs. the sham group. Pnx, pinealectomy; PGTT, peritoneal glucose tolerance test; OP, operation.

\section{Results}

Pnx increases insulin sensitivity. Before rats underwent Pnx, average body weight was $465 \pm 22.3 \mathrm{~g}$. Average body weight at the end of the experiment was $542 \pm 17.5 \mathrm{~g}$ in the sham group and $529 \pm 28.1 \mathrm{~g}$ in the Pnx group. Although not statistically different, throughout the experiment the degree of increase in the body weight of the Pnx group was consistently less than that observed in the sham group (Fig. 1A). PGTT before the operation revealed impaired insulin responses. After the operation, PGTT revealed that glucose levels at 60,90 and $120 \mathrm{~min}$ in the Pnx group were lower than those in the sham group, which indicated an improvement of insulin sensitivity in the Pnx group (Fig. 1B). Food and water intake/100 g body weight did not differ between the two groups (Fig. 1C and D). Since insulin resistance is associated with elevated levels of plasma leptin, circulating leptin levels in the sham and Pnx groups were investigated and calculated as leptin levels per $100 \mathrm{~g}$ body weight (Fig. 1E). Circulating leptin levels in the Pnx group significantly decreased $(159.79 \pm 13.39 \mathrm{pg} / \mathrm{ml} ; \mathrm{P}<0.01)$ compared with those in the sham group $(344.67 \pm 48.64 \mathrm{pg} / \mathrm{ml}$; $\mathrm{P}<0.05)$, implicating increased insulin sensitivity following Pnx. Serum insulin levels were also determined in sham and Pnx groups and, although not statistically significant, decreased insulin levels were found in the Pnx group (data not shown). Serum levels of melatonin were also determined, but the measured values were below the detectable levels of the kit (data not shown).

Pnx decreases melatonin receptor (MTNR)1A and MTNRIB expression in WAT and BAT. To determine the effect of Pnx on the expression of melatonin receptors, the expression levels of MTNR1A and MTNR1B were examined in WAT and BAT. It was found that both mRNA (Fig. 2A and B) and protein (Fig. 2C and D) expression levels of MTNR1A and MTNR1B decreased in WAT from the group that underwent Pnx compared with those in the sham group. Although mRNA levels of MTNR1A and MTNR1B were not different in BAT, proteins expression levels of both MTNR1A and MTNR1B were significantly different, which indicates decreased melatonin receptor activity in WAT and BAT. Further research as to why and how expression levels of melatonin receptor mRNA do not match those of melatonin receptor proteins is required.

Pnx stimulates thermogenesis in BAT. Based on the results that showed increased insulin sensitivity, and decreased MTNR1A and MTNR1B expression, in WAT and BAT in the Pnx group, it was hypothesized that Pnx improved insulin sensitivity by stimulating thermogenesis in BAT and regulating lipogenesis in WAT. To investigate this hypothesis, the expression of various thermogenic genes were examined in BAT (Fig. 3A). Fig. 3A shows a notable increase in the expression levels 

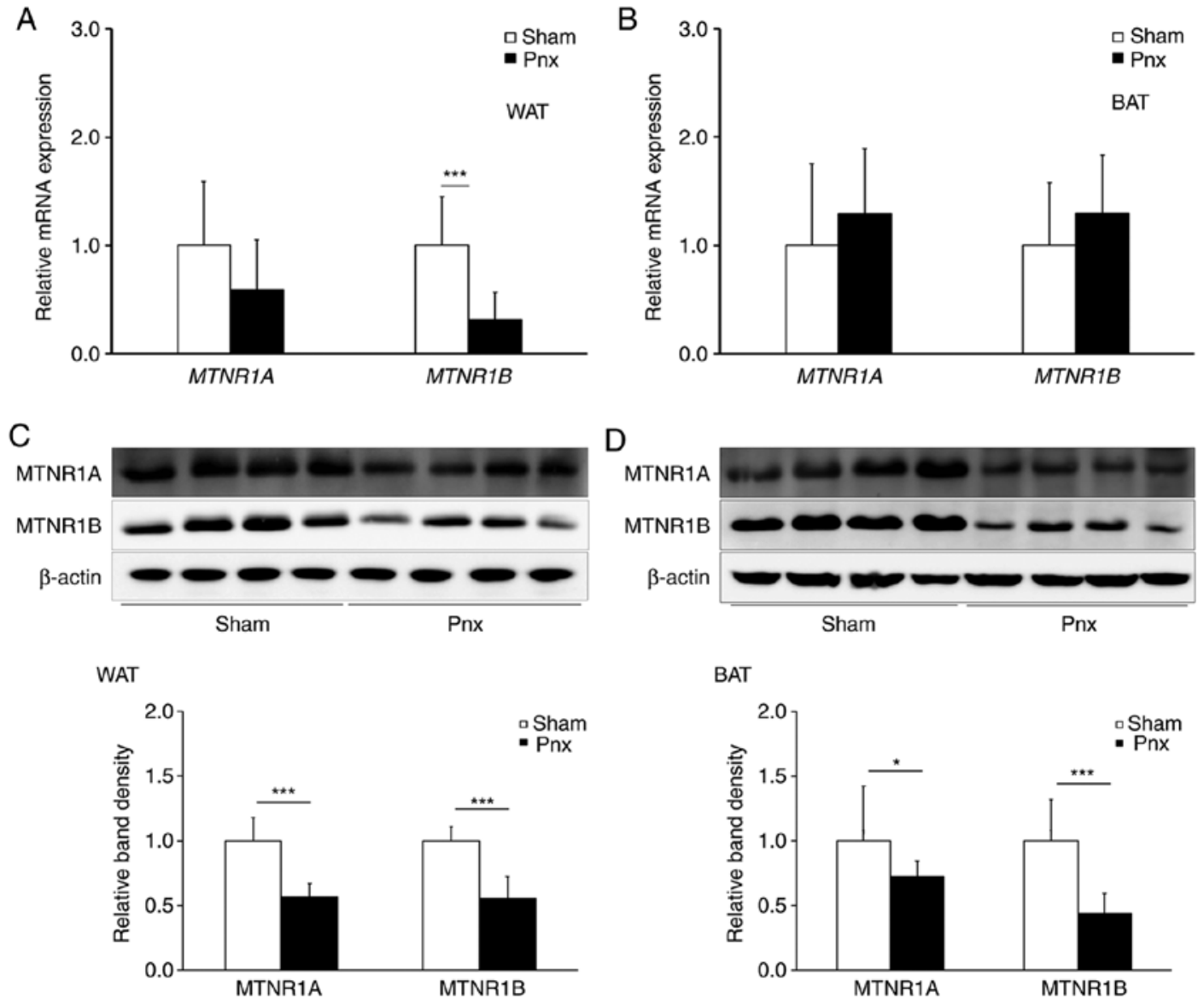

Figure 2. Expression of MTNR1A and MTNR1B in WAT and BAT. mRNA expression levels of MTNR1A and MTNR1B in (A) WAT and (B) BAT were examined by reverse transcription-quantitative PCR and normalized to $\beta$-actin. Protein expression levels of MTNR1A and MTNR1B in (C) WAT and (D) BAT were examined by western blotting. Values are presented as the mean $\pm \mathrm{SD} .{ }^{*} \mathrm{P}<0.05,{ }^{* * * *} \mathrm{P}<0.001$ vs. the sham group. Pnx, pinealectomy; WAT, white adipose tissue; BAT, brown adipose tissue; MTNR, melatonin receptor.

(upper panel) and semi-quantification (lower panel) of the thermogenic genes (SIRT1, PGC1 $\alpha$, UCP1 and DIO2) in the groups that underwent Pnx compared with those in the sham group. The invisibility of the SIRT and PGC1 $\alpha$ western bands in the control may be due to short exposure time. Accordingly, increased mRNA expression of PGC1 $\alpha$, UCP1, DIO2 and PR domain-containing 16 (PRDM16) were also found in the Pnx group (Fig. 3B and C). However, no differences were observed in the expression levels of peroxisome proliferator-activated receptor $\gamma$ (data not shown), the master regulator of adipogenesis $(21,22)$.

To further validate the thermogenic effect of Pnx, the study proceeded to examine histological changes and UCP1 expression in BAT (Fig. 3D). Histological analysis of BAT by H\&E staining revealed a marked decrease in the size of lipid droplets in the Pnx group (upper right panel, Fig. 3D). Consistent with the result in Fig. 3A and $\mathrm{B}$, immunohistochemical staining revealed a notable increase in the expression of UCP1 in the Pnx group compared with the sham group (lower right panel, Fig. 3D).

Pnx downregulates lipogenic genes in WAT and the liver. Subsequently, the possible regulatory effects of Pnx in WAT were examined by determining the expression levels of various lipogenic genes (Fig. 4A). It was found that Pnx led to a significant reduction in the expression of sterol regulatory element binding protein 1c (SREBP1c), the master regulatory transcription factor for lipogenesis (21). Consistent with the decreased expression of SREBP1c, the Pnx group was also found to have a decreased expression of fatty acid synthase (FASN), a key lipogenic enzyme in the first step of de novo lipogenesis (21). Moreover, following Pnx the expression of stearoyl-CoA desaturase (SCD1), which catalyzes the unsaturation of fatty acids forming a double bond in stearoyl-CoA, decreased in these rats. These results suggested that Pnx inhibited the lipogenic pathway in WAT. Next, the effect of Pnx on the expression of major mitochondrial biogenesis genes PGC1 $\alpha$ and cytochrome c (Cyt c) was investigated (21). Contrary to the expression in BAT (Fig. 3A and B), the expression of PGC1 $\alpha$ in WAT decreased following Pnx, which might indicate attenuated mitochondrial biogenesis. Decreased expression levels of genes involved in fatty acid oxidation [carnitine palmitoyltransferase (CPT) $1 \mathrm{~b}$ and medium-chain acyl-CoA dehydrogenase], also supports this hypothesis (Fig. 4B) (21).

Since the liver is the organ primarily responsible for lipogenesis, the expression levels of lipogenic genes were further examined in the liver. Histological analysis of the liver by H\&E staining also demonstrated that lipid droplets decreased in size and number in the Pnx group compared with the sham group 
A
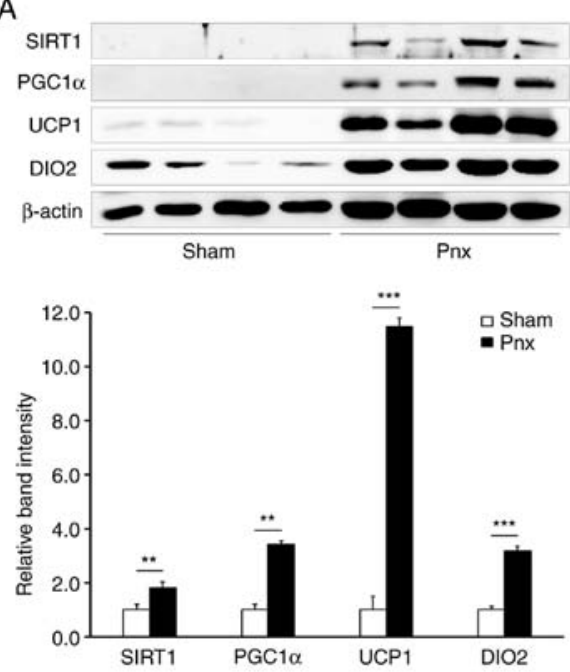

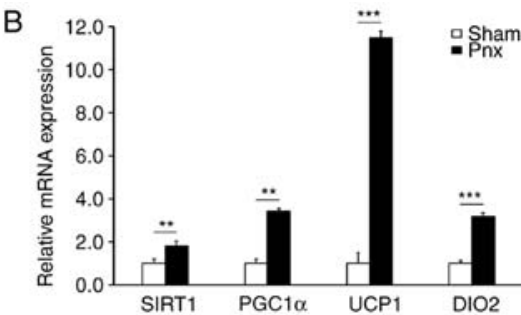

C

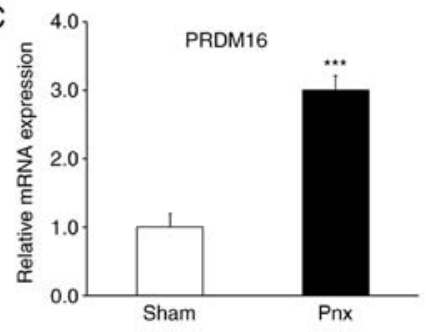

D

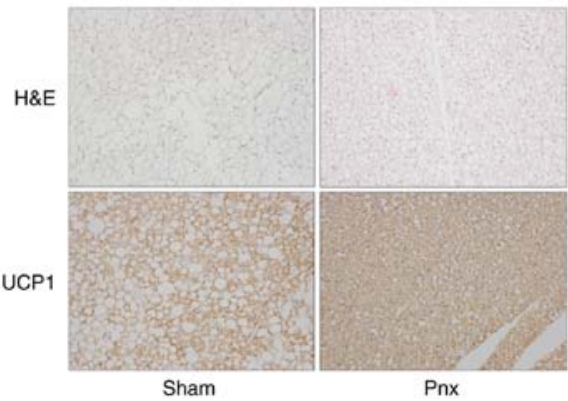

Figure 3. Thermogenic genes and PRDM16 in BAT. (A) Protein expression of SIRT1, PGC1 $\alpha$, UCP1 and DIO2 were examined by western blot analysis (upper panel), and relative band density was semi-quantified (lower panel). (B) mRNA expression levels of PGC1 $\alpha$, UCP1, and DIO2 (C) PRDM16 was examined by reverse transcription-quantitative PCR and normalized to $\beta$-actin. (D) Changes in size of lipid droplets and UCP1 expression in BAT. Representative images of BAT from the sham group and Pnx group stained with H\&E (upper panel) and immune-histochemical images stained with UCP1 antibody (lower panel). Magnification, $\mathrm{x} 200$. Values are presented as the mean $\pm \mathrm{SD} .{ }^{* * *} \mathrm{P}<0.01,{ }^{* * * *} \mathrm{P}<0.001$ vs. the sham group. Pnx, pinealectomy; BAT, brown adipose tissue; PGC1 $\alpha$, peroxisome proliferator-activated receptor $\gamma$ coactivator 1- $\alpha$; UCP1, uncoupling protein 1; PPAR $\gamma$, peroxisome proliferator-activated receptor $\gamma$; DIO2, deiodinase 2; PRDM16, PR domain 16; H\&E, hematoxylin and eosin; SIRT1, sirtuin 1.
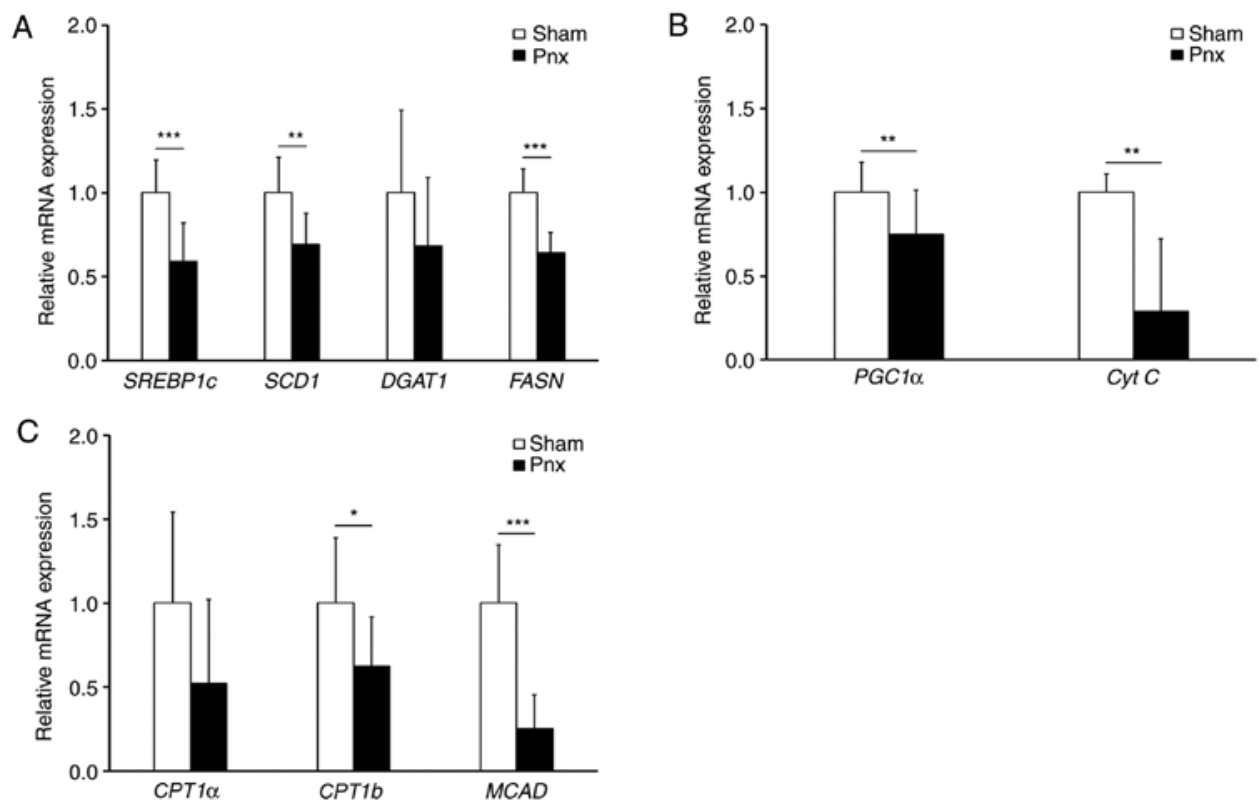

Figure 4. Lipogenesis genes in WAT. mRNA expression levels of (A) the lipogenic genes, SREBP1c, SCD1, DGAT1 and FASN, (B) the mitochondrial biogenesis genes, PGCl $\alpha$ and Cyt C, and (C) fatty acid oxidation genes, CPT1a, CPT1b and MCAD, in WAT were examined by reverse transcription-quantitative PCR and normalized to $\beta$-actin. Values are presented as the mean $\pm \mathrm{SD}$. ${ }^{*} \mathrm{P}<0.05,{ }^{, *} \mathrm{P}<0.01,{ }^{* * *} \mathrm{P}<0.001$ vs. the sham group. Pnx, pinealectomy; WAT, white adipose tissue; SREBP1c, sterol regulatory element-binding protein 1; SCD1, stearoyl-CoA desaturase 1; DGAT1, diacylglycerol O-acyltransferase 1; FASN, fatty acid synthase; CPT, carnitine palmitoyltransferase; MCAD, medium-chain acyl-CoA dehydrogenase; PGCl $\alpha$, peroxisome proliferator-activated receptor $\gamma$ coactivator 1- $\alpha$; Cyt C, cytochrome c. 
A
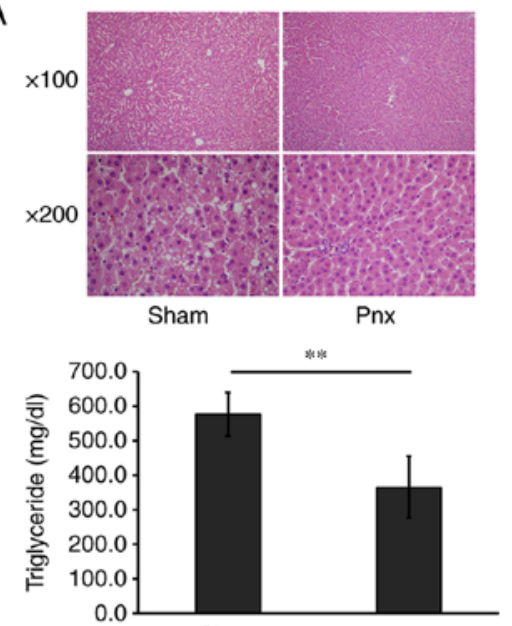

C

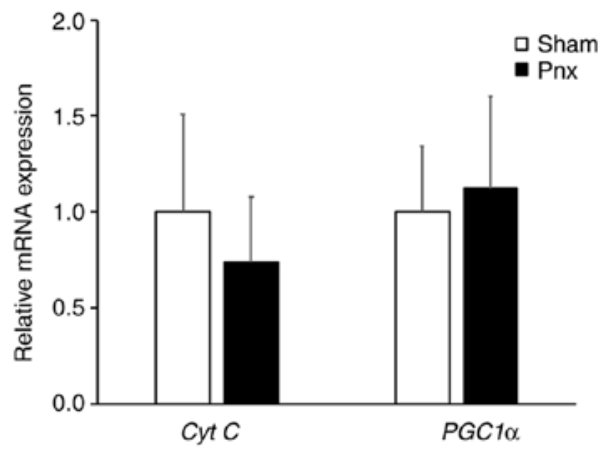

B

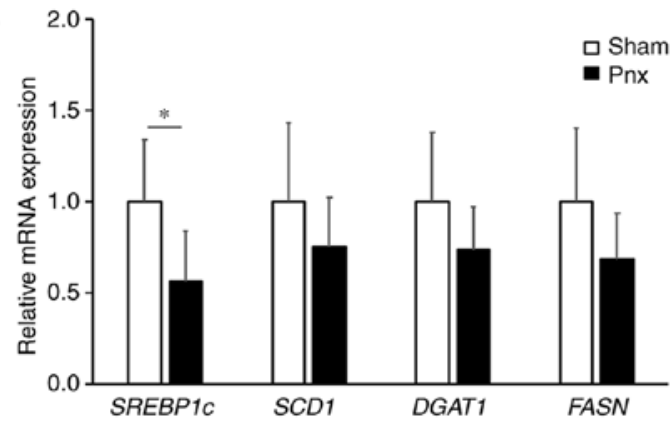

$\mathrm{E}$
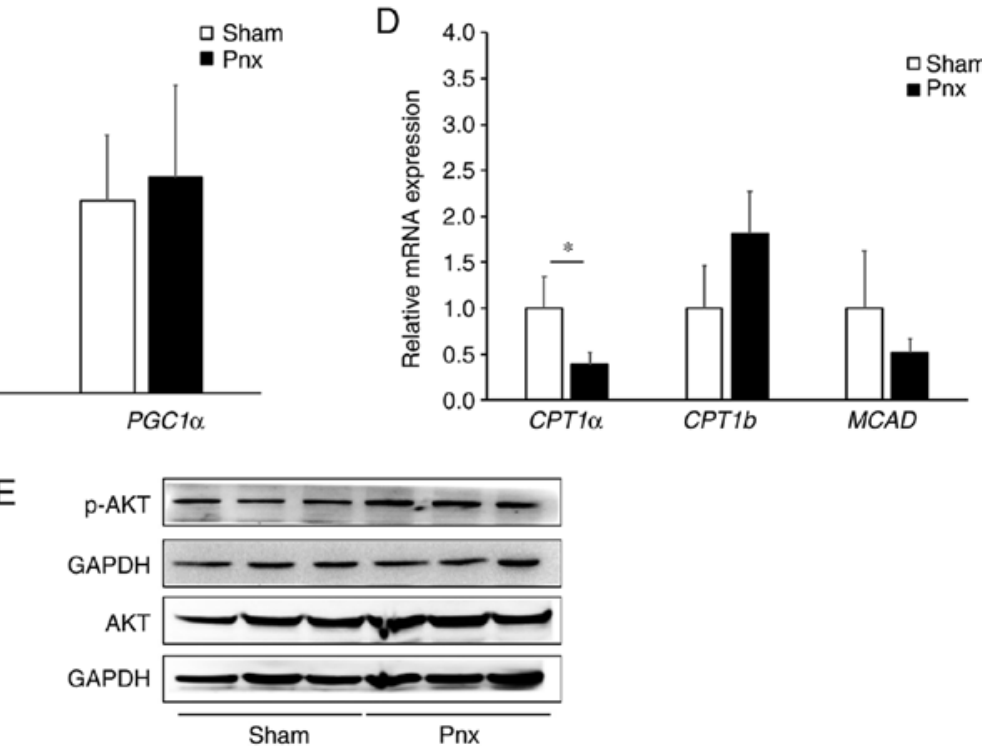

Figure 5. Changes in hepatic histology and lipogenesis genes in the liver. (A) Liver sections were stained with H\&E. Magnification at $\mathrm{x} 100$ in the upper panel and x200 in the lower panel. mRNA expression levels of the (B) lipogenic genes, SREBP1c, SCD1, DGAT1 and FASN, (C) mitochondrial biogenesis genes, PGC1 $\alpha$ and Cyt C, and (D) fatty acid oxidation genes, CPT1a, CPT1b and MCAD, in the liver were examined by reverse transcription-quantitative PCR and normalized to $\beta$-actin. (E) Protein expression levels of p-AKT, AKT and GAPDH were examined by western blotting. Values are presented as the mean \pm SD. ${ }^{*} \mathrm{P}<0.05,{ }^{* *} \mathrm{P}<0.01$ vs. the sham group. Pnx, pinealectomy; SREBP1c, sterol regulatory element-binding protein 1; SCD1, stearoyl-CoA desaturase 1; DGAT1, diacylglycerol O-acyltransferase 1; FASN, fatty acid synthase; CPT, carnitine palmitoyltransferase; MCAD, medium-chain acyl-CoA dehydrogenase; PGCl $\alpha$, peroxisome proliferator-activated receptor $\gamma$ coactivator 1- $\alpha$; Cyt C, cytochrome c; H\&E, hematoxylin and eosin; p-, phosphorylated.

(Fig. 5A). Consistent with the results of the expression levels in WAT, it was found that Pnx induced a significant decrease in SREBP1c. Furthermore, the expression levels of the SREPB1c target genes, SCD1, FASN and DGAT2, although not statistically significant, decreased in the group that underwent Pnx (Fig. 5B). Expression levels of genes involved in mitochondrial biogenesis and fatty acid oxidation, with the exception of CPT1a, showed no significant differences between the sham and Pnx groups (Fig. 5C and D). The present study also observed an increased expression of phosphorylated AKT in the Pnx group (Fig. 5E).

\section{Discussion}

Numerous studies have demonstrated that exogenous melatonin reduces body weight and food intake (14-17). However, the current study has shown that Pnx stimulated thermogenesis in BAT, and attenuated lipogenesis in WAT and the liver of HFD-fed rats without any significant changes in body weight compared with control rats.

No differences were observed in the body weight or amount of food intake in the group that underwent Pnx compared with those in the sham group, which may indicate that endogenously synthesized pineal melatonin does not affect systemic energy balance. To support this result, a recent study also demonstrated that there was no difference in the body weight and food intake of NCD-fed controls and Pnx rats (23). Buonfiglio et al (23) reported that exogenous melatonin treatment following Pnx resulted in a decrease in body weight and food intake, which suggests that exogenous, rather than endogenous, melatonin is a possible contributing factor for the decrease in body weight and food intake. Decreased protein expression levels of MTNR1A and MTNR1B in WAT and BAT of the Pnx group were also observed, which 
suggests reduced melatonin receptor activities in WAT and BAT. Furthermore, it was found that mRNA expression levels of MTNR1A and MTNR1B were not consistent with protein expression levels of MTNR1A and MTNR1B in BAT, which may indicate that there is a different response to compensate for decreased concentrations of melatonin in WAT and BAT.

Notably, despite the lack of significant differences in body weight changes, Pnx was observed to increase insulin sensitivity, evidenced by faster disposal of plasma glucose and lower levels of plasma leptin in the Pnx group. These results are in contrast to a previous report, which found that Pnx induced insulin resistance (24). Lima et al (24) demonstrated that Pnx causes glucose intolerance and decreases adipose cell responsiveness to insulin in NCD-fed rats. Since HFD-fed rats were employed in the present study, it was hypothesized that there was an interaction between diet and the absence of pineal melatonin that affected systemic metabolism. In the present study, decreased expression levels of lipogenic genes were observed in WAT, which indicated a reduction in lipogenesis. Whether the decreased lipogenesis in WAT contributed to the decreased adiposity in the Pnx group needs further study since lipogenesis in WAT under a HFD may not be as tightly associated with the adiposity caused by a NCD. It is commonly known that leptin levels increase in obesity and are associated with insulin resistance (25-28), so decreased leptin levels in the Pnx group compared with that in the control HFD-fed group further validates Pnx-induced insulin sensitivity.

UCP1, also known as thermogenin, is predominantly expressed in BAT. UCP1 is a mitochondrial protein that regulates dissipation of excess energy via the uncoupling of oxidative phosphorylation (21). It is also positively associated with insulin sensitivity (22). The present study found that Pnx markedly increased the expression of UCP1 in BAT. Consistent with this finding, increased expression levels of PGC1 $\alpha$, DIO2 and SIRT1 were also found in the Pnx group. UCP1 plays a role in the activity of several transcription factors and genes, such as PGC1 $\alpha$, DIO2, SIRT1 and PRDM16 (21). PGC1 $\alpha$ is a master nuclear transcription factor that controls the expression of thermogenic genes (21). In the present study, PGC1 $\alpha$ expression was significantly increased in the Pnx rats, which suggested that PGC1 $\alpha$-induced thermogenic genes are upregulated following Pnx. DIO2 is another commonly known master regulatory molecule that controls the expression of thermogenic genes (29). The present study also found that Pnx stimulated the expression of DIO2. As expected, the expression of the thermogenic gene UCP1 was increased in the BAT following Pnx. Furthermore, DIO2 activity has been demonstrated to generate a significant fraction of the circulating hormone triiodothyronine in rats, and enhance the cAMP-generated acute increase in UCP1 mRNA via increased UCP1 gene transcription (30). PRDM16 is a regulatory molecule known to induce brown adipogenicity (31), and the expression of PRDM16 in the BAT of the Pnx group was found to be increased, which indicated that Pnx may induce BAT. Furthermore, the expression of SIRT1 in the Pnx group was found to increase the expressions of SIRT1 in BAT, which further indicated that the Pnx-induced insulin sensitivity may be mediated via BAT activation (32). The present study is limited by the absence of a control group of rats fed NCD. Furthermore, this study lacks an investigation into the underlying mechanisms of the effect of Pnx on BAT activation. Therefore, further studies are required to elucidate this.

Overall, in the present study Pnx was found to decrease lipogenesis in WAT and the liver. It was also demonstrated that expression levels of lipogenic genes were decreased in both the WAT and liver of the Pnx group compared with the sham group, which indicated that Pnx attenuates lipogenesis via a currently unidentified mechanism. These results indicate that Pnx may inhibit lipogenic activity by inhibiting the expression of genes involved in lipogenesis, as evidenced by the decrease in mRNA expression of the mitochondrial biogenesis genes, PGC1 $\alpha$ and Cyt C. In conclusion, rats that underwent Pnx experience an increase in thermogenesis in BAT, and a decrease in lipogenesis in WAT, leading to increased insulin sensitivity.

\section{Acknowledgements}

Not applicable.

\section{Funding}

This work was supported by the Basic Science Research Program through the National Research Foundation of Korea funded by the Ministry of Education (grant no. NRF -2018R1A2B6006175) and by the research fund of Hanyang University (grant no. HY-201500000003026), Seoul, Republic of Korea.

\section{Availability of data and materials}

The datasets used and/or analyzed during the current study are available from the corresponding author on reasonable request.

\section{Authors' contributions}

This study was conceptualized by EH and JHS, data collection was performed by MK and SML. Data analysis was conducted by MK, SML, JJ and YJK, the experiments were performed by MK, SML, JJ, KCM and EH. EH, JJ, KCM, JHS and TKH supervised the project, and data processing was performed by KCM. This study was supported by funding acquired by EH, JHS and TKH. The initial draft of the manuscript was written by MK, SML and KCM, and the review and editing were conducted by EH, JHS and TKH. TKH supervised additional experiments, analyzed and interpreted the data, provided funding and prepared the draft for revision. All authors read and approved the final manuscript.

\section{Ethics approval and consent to participate}

Not applicable.

\section{Patient consent for publication}

Not applicable.

\section{Competing interests}

The authors declare that they have no competing interests. 


\section{References}

1. Ng M, Fleming T, Robinson M, Thomson B, Graetz N, Margono C Mullany EC, Biryukov S, Abbafati C, Ferede S, et al: Global, regional, and national prevalence of overweight and obesity in children and adults during 1980-2013: A systematic analysis for the global burden of disease study 2013. Lancet 384: 766-781, 2014.

2. Berrington de Gonzalez A, Hartge P, Cerhan JR, Flint AJ, Hannan L, MacInnis RJ, Moore SC, Tobias GS, Anton-Culver H, Freeman LB, et al: Body-mass index and mortality among 1.46 million white adults. N Engl J Med 363: 2211-2219, 2010.

3. Renehan AG, Tyson M, Egger M, Heller RF and Zwahlen M Body-mass index and incidence of cancer: A systematic review and meta-analysis of prospective observational studies. Lancet 371: 569-578, 2008.

4. Prospective Studies Collaboration; Whitlock G, Lewington S, Sherliker P, Clarke R, Emberson J, Halsey J, Qizilbash N, Collins R and Peto R: Body-mass index and cause-specific mortality in 900000 adults: Collaborative analyses of 57 prospective studies. Lancet 373: 1083-1096, 2009.

5. Skrypnik D, Bogdański P,Zawiejska A and Wender-Ożegowska E: Role of gestational weight gain, gestational diabetes, breastfeeding, and hypertension in mother-to-child obesity transmission. Pol Arch Intern Med 129: 267-275, 2019.

6. Olshansky SJ, Passaro DJ, Hershow RC, Layden J, Carnes BA Brody J, Hayflick L, Butler RN, Allison DB and Ludwig DS: A potential decline in life expectancy in the United States in the 21st century. N Engl J Med 352: 1138-1145, 2005.

7. Stehle JH, Saade A, Rawashdeh O, Ackermann K, Jilg A, Sebestény T and Maronde E: A survey of molecular details in the human pineal gland in the light of phylogeny, structure, function and chronobiological diseases. J Pineal Res 51: 17-43, 2011.

8. Cardinali DP, Golombek DA, Rosenstein RE, Cutrera RA and Esquifino AI: Melatonin site and mechanism of action: Single or multiple? J Pineal Res 23: 32-39, 1997.

9. Galano A, Tan DX and Reiter RJ: Melatonin as a natural ally against oxidative stress: A physicochemical examination. J Pineal Res 51: 1-16, 2011.

10. Reiter RJ, Tan DX, Osuna C and Gitto E: Actions of melatonin in the reduction of oxidative stress. A review. J Biomed Sci 7 : 444-458, 2000

11. Cipolla-Neto J, Amaral FG, Afeche SC, Tan DX and Reiter RJ: Melatonin, energy metabolism, and obesity: A review. J Pineal Res 56: 371-381, 2014.

12. Bartness TJ and Wade GN: Body weight, food intake and energy regulation in exercising and melatonin-treated siberian hamsters. Physiol Behav 35: 805-808, 1985.

13. Bubenik G and Pang SF: The role of serotonin and melatonin in gastrointestinal physiology: Ontogeny, regulation of food intake, and mutual serotonin-melatonin feedback. J Pineal Res 16: 91-99, 1994.

14. Bojkova B, Orendáš P, Friedmanova L, Kassayová M, Datelinka I, Ahlersová E and Ahlers I: Prolonged melatonin administration in 6-month-old sprague-dawley rats: Metabolic alterations. Acta Physiol Hung 95: 65-76, 2008.

15. Puchalski SS, Green JN and Rasmussen DD: Melatonin effect on rat body weight regulation in response to high-fat diet at middle age. Endocrine 21: 163-167, 2003.

16. Ríos-Lugo MJ, Jiménez-Ortega V, Cano-Barquilla P, Mateos PF, Spinedi EJ, Cardinali DP and Esquifino AI: Melatonin counteracts changes in hypothalamic gene expression of signals regulating feeding behavior in high-fat fed rats. Horm Mol Biol Clin Investig 21: 175-183, 2015.

17. Wolden-Hanson T, Mitton DR, McCants RL, Yellon SM, Wilkinson CW, Matsumoto AM and Rasmussen DD: Daily melatonin administration to middle-aged male rats suppresses body weight, intraabdominal adiposity, and plasma leptin and insulin independent of food intake and total body fat Endocrinology 141: 487-497, 2000.
18. Piccinetti CC, Migliarini B, Olivotto I, Coletti G, Amici A and Carnevali O: Appetite regulation: The central role of melatonin in danio rerio. Horm Behav 58: 780-785, 2010.

19. Alonso-Vale MIC, Andreotti S, Mukai PY, Borges-Silva CDN, Peres SB, Cipolla-Neto J and Lima FB: Melatonin and the circadian entrainment of metabolic and hormonal activities in primary isolated adipocytes. J Pineal Res 45: 422-429, 2008.

20. Maganhin CC, Simões RS, Fuchs LFP, Oliveira-Filho RM, de Jesus Simões M, Neto JE, Baracat EC and Maria J: Rat pinealectomy: A modified direct visual approach. Acta Cir Bras 24: 321-324, 2009.

21. Seale P, Kajimura S, Yang W, Chin S, Rohas LM, Uldry M, Tavernier G, Langin D and Spiegelman BM: Transcriptional control of brown fat determination by PRDM16. Cell Metab 6: 38-54, 2007.

22. Chondronikola M, Volpi E, Børsheim E, Porter C, Annamalai P, Enerbäck S, Lidell ME, Saraf MK, Labbe SM, Hurren NM, et al: Brown adipose tissue improves whole body glucose homeostasis and insulin sensitivity in humans. Diabetes 63: 4089-4099, 2014.

23. Buonfiglio D, Parthimos R, Dantas R, Silva RC, Gomes G, Andrade-Silva J, Ramos-Lobo A, Amaral FG, Matos R, Sinésio J Jr, et al: Melatonin absence leads to long-term leptin resistance and overweight in rats. Front Endocrinol (Lausanne) 9: 122,2018

24. Lima FB, Machado UF, Bartol I, Seraphim PM, Sumida DH, Moraes SM, Hell NS, Okamoto MM, Saad MJ, Carvalho CR and Cipolla-Neto J: Pinealectomy causes glucose intolerance and decreases adipose cell responsiveness to insulin in rats. Am J Physiol 275: E934-E941, 1998.

25. Considine RV, Sinha MK, Heiman ML, Kriauciunas A, Stephens TW, Nyce MR, Ohannesian JP, Marco CC, McKee LJ and Bauer TL: Serum immunoreactive-leptin concentrations in normal-weight and obese humans. N Engl J Med 334: 292-295, 1996.

26. Handjieva-Darlenska T and Boyadjieva NJ: The effect of high-fat diet on plasma ghrelin and leptin levels in rats. J Physiol Biochem 65: 157-164, 2009.

27. Segal KR, Landt M and Klein S: Relationship between insulin sensitivity and plasma leptin concentration in lean and obese men. Diabetes 45: 988-991, 1996.

28. Skrypnik D, Mostowska A, Jagodziński PP and Bogdański P: Association of rs699947 (-2578 C/A) and rs2010963 (-634 G/C) single nucleotide polymorphisms of the VEGF gene, VEGF-A and leptin serum level, and cardiovascular risk in patients with excess body mass: A case-control study. J Clin Med 9: 469, 2020

29. Bartelt A and Heeren J: Adipose tissue browning and metabolic health. Nat Rev Endocrinol 10: 24-36, 2014.

30. De Jesus LA, Carvalho SD, Ribeiro MO, Schneider M, Kim SW, Harney JW, Larsen PR and Bianco AC: The type 2 iodothyronine deiodinase is essential for adaptive thermogenesis in brown adipose tissue. J Clin Invest 108: 1379-1385, 2001.

31. Giralt $\mathrm{M}$ and Villarroya F: White, brown, beige/brite: Different adipose cells for different functions? Endocrinology 154: 2992-3000, 2013

32. Boutant M, Joffraud M, Kulkarni SS, García-Casarrubios E, García-Roves PM, Ratajczak J, Fernández-Marcos PJ, Valverde AM, Serrano M and Cantó C: SIRT1 enhances glucose tolerance by potentiating brown adipose tissue function. Mol Metab 4: 118-131, 2014.

This work is licensed under a Creative Commons Attribution-NonCommercial-NoDerivatives 4.0 International (CC BY-NC-ND 4.0) License. 